\title{
A review of the effectiveness of agriculture interventions in improving nutrition outcomes
}

\author{
Peter R Berti* , Julia Krasevec and Sian FitzGerald \\ PATH Canada (Programme for Appropriate Technology in Health), 1 Nicholas Street, Suite 1 105, Ottawa, Ontario, \\ Canada, K1N 7B7
}

Submitted 7 July 2003: Accepted 17 December 2003

\begin{abstract}
Objectives: To review the impact of agriculture interventions on nutritional status in participating households, and to analyse the characteristics of interventions that improved nutrition outcomes.

Design: We identified and reviewed reports describing 30 agriculture interventions that measured impact on nutritional status. The interventions reviewed included home gardening, livestock, mixed garden and livestock, cash cropping, and irrigation. We examined the reports for the scientific quality of the research design and treatment of the data. We also assessed whether the projects invested in five types of 'capital' (physical, natural, financial, human and social) as defined in the Sustainable Livelihoods Framework, a conceptual map of major factors that affect people's livelihoods.

Results: Most agriculture interventions increased food production, but did not necessarily improve nutrition or health within participating households. Nutrition was improved in 11 of 13 home gardening interventions, and in 11 of 17 other types of intervention. Of the 19 interventions that had a positive effect on nutrition, 14 of them invested in four or five types of capital in addition to the agriculture intervention. Of the nine interventions that had a negative or no effect on nutrition, only one invested in four or five types of capital.

Conclusions: Those agriculture interventions that invested broadly in different types of capital were more likely to improve nutrition outcomes. Those projects which invested in human capital (especially nutrition education and consideration of gender issues), and other types of capital, had a greater likelihood of effecting positive nutritional change, but such investment is neither sufficient nor always necessary to effect change.
\end{abstract}

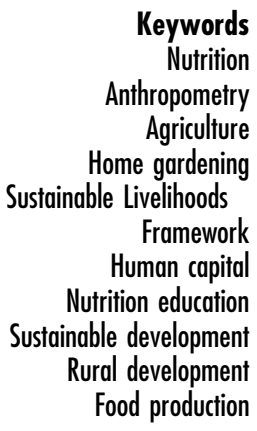

Keywords

ropometry gardening elihoods

Framework Human capital

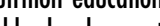

Rural development Food production
This report critically reviews the literature concerning the effectiveness of agriculture interventions in improving nutritional status in participating households. The central question that is addressed in the review is: 'Do agricultural interventions improve nutritional status in the participating households?' The secondary question is: 'What are the characteristics of those interventions that improve nutritional status, and what are the characteristics of those that do not?' We accept that well-conducted agriculture interventions increase productivity and food availability, and it would be intuitive to accept the hypothesis that agriculture interventions also improve nutrition; surely more food will lead to improved nutrition? Perhaps because the link appears obvious, there has not been much research to test the hypothesis. Nevertheless, the hypothesis has long been debated ${ }^{1,2}$ and it is understood that a complex relationship exists between production, income and nutrition ${ }^{3}$. The growing consensus is that the union between agriculture and nutrition requires cultural, economic and social conditioning factors ${ }^{4,5}$. In this review, this consensus is considered, and ultimately supported, through a review of primary literature and reports from the grey literature, considering both the effects observed during the life of the project and the likelihood of longerterm sustainable changes.

\section{Methods}

\section{Literature search}

We conducted a comprehensive review of the primary (peer-reviewed) literature and an extensive review of the grey literature. All studies included in the review had a nutrition monitoring component.

A primary literature search was done on Medline, Current Contents, Biosis Previews, PASCAL and AGRIS in November 2001, using the following keywords: (agricult* OR 'sustainable development' OR 'rural development' OR 'food production' OR farm OR garden) AND (nutrition* OR 
anthropom* OR diet* OR 'child growth'), and was limited to human investigations and year of publication between 1985 and 2001. Twenty-two papers, including one review, were identified. Two additional peer-reviewed papers were identified and obtained using references from the review (pre-1985 references).

The grey literature search involved reference lists from other papers, the websites of the International Center for Research on Women (www.icrw.org), the International Food Policy Research Institute (www.ifpri.org) and the United States Agency for International Development (www.usaid.gov), discussions with colleagues and searches of their personal libraries, and searches using the University of Ottawa catalogue ORBIS. The grey literature yielded 10 relevant reports.

Although the topic is often talked about, debated and highlighted in policy documents, we did not find any similar previous papers that systematically reviewed the nutrition outcomes of agriculture interventions.

\section{Review methods}

The authors individually reviewed the papers and reports, and prepared summaries (available in an extended report $\left.{ }^{6}\right)$. The authors reviewed one another's summaries, sought clarification on discrepancies, and reviewed the original papers if doubts remained. The papers were summarised according to type of intervention, study/ project design and description, agriculture indicators, agriculture outcomes, nutrition indicators, nutrition outcomes, and authors' conclusions. The reports were also summarised according to the inclusion of five types of 'capital' (natural, physical, human, social, financial) described in the Sustainable Livelihoods Framework ${ }^{3,7}$. The papers were given a subjective ranking of 'high', 'mid' or 'low', reflecting the level of confidence we had in the authors' conclusions regarding the agriculture-nutrition relationship, and therefore the relative weighting that the paper had on our conclusions. A high ranking was given to papers with baseline surveys, control groups, appropriate agriculture and nutrition indicators, appropriate sample size, and appropriate collection of agriculture and nutrition data.

In total, we reviewed 24 peer-reviewed primary research papers, two projects from one peer-reviewed review paper, one report from conference proceedings, and 10 project reports/monographs. Because of overlap between some papers, the number of projects reviewed was less than the total number of papers/reports, yielding a total of 30 actual projects: 13 vegetable/home gardening, two livestock, two mixed livestock/gardening, eight cash cropping, two irrigation, and three other (land redistribution, promotion of production with credit and extension services, duck-fish production system).

Some projects fit into more than one category (for example, vegetable production for commercial purposes, irrigation to increase production of cash crops, etc.) and were assigned to the category that figured most prominently in the report. The projects reviewed were based in Africa (12, mostly north-east), Asia (14, south and south-east) and the Americas (four).

\section{The Sustainable Liveliboods Framework}

The Sustainable Livelihoods Framework is a conceptual map of major factors that affect people's livelihoods, and the relationships that exist among them. It is presented here as a meaningful perspective for understanding the relationship between agriculture interventions and nutrition outcomes. The Sustainable Livelihoods Framework emphasises five different types of capital or assets that can be supported and strengthened in any development intervention: physical, financial, social, human and natural $^{3,7}$. A graphical representation of the framework can be viewed at http://www.livelihoods.org/info/ guidance_sheets_pdfs/section2.pdf.

We credited the intervention with having supported or strengthened the various capitals according to the guidelines in Table 1.

\section{Results}

The findings of the reviewed reports are summarised in Table 2. Of the 30 projects reviewed, 20 measured agriculture outcomes ${ }^{4,8-17,21,25,27-34,38,39}$ and 17 of these showed some improvement in at least one agriculture indicator $^{4,8-12,14-17,25,28,30,32,33,39}$.

All of the studies included in the review had a nutrition monitoring component. Among them, the intervention group showed improvement and/or better status than the

Table 1 'Flags' by which investments in the various capitals were identified*

\begin{tabular}{|c|c|c|c|c|}
\hline Natural capital & Physical capital & Social capital & Human capital & Financial capital \\
\hline $\begin{array}{l}\text { Use of sustainable } \\
\text { agriculture practices } \\
\text { Intensification of } \\
\text { existing systems } \\
\text { Diversification by } \\
\text { adding new systems }\end{array}$ & $\begin{array}{l}\text { Support the increase } \\
\text { in land, tools, livestock, etc. }\end{array}$ & $\begin{array}{l}\text { Using social and } \\
\text { participatory processes }\end{array}$ & $\begin{array}{l}\text { Agriculture training } \\
\text { programmes } \\
\text { Nutrition education } \\
\text { programmes } \\
\text { Other training } \\
\text { programmes } \\
\text { Gender considerations }\end{array}$ & $\begin{array}{l}\text { Access to credit, } \\
\text { grants, subsidies } \\
\text { Value-added products } \\
\text { Value-added marketing } \\
\text { Other financial benefits }\end{array}$ \\
\hline
\end{tabular}

*Other types of flags are possible. All of those that occurred in the reviewed papers fit into one of these listed flags. 


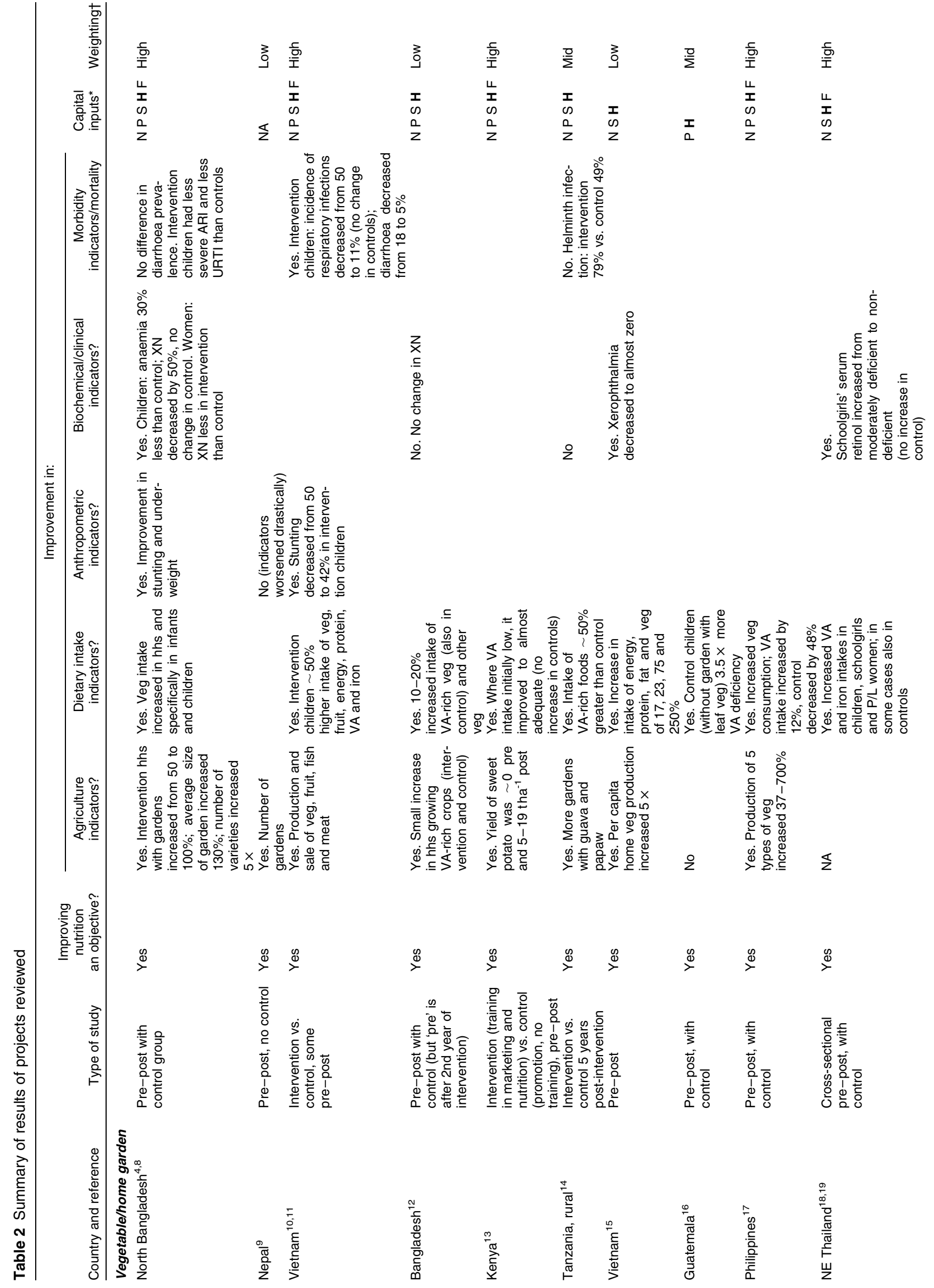




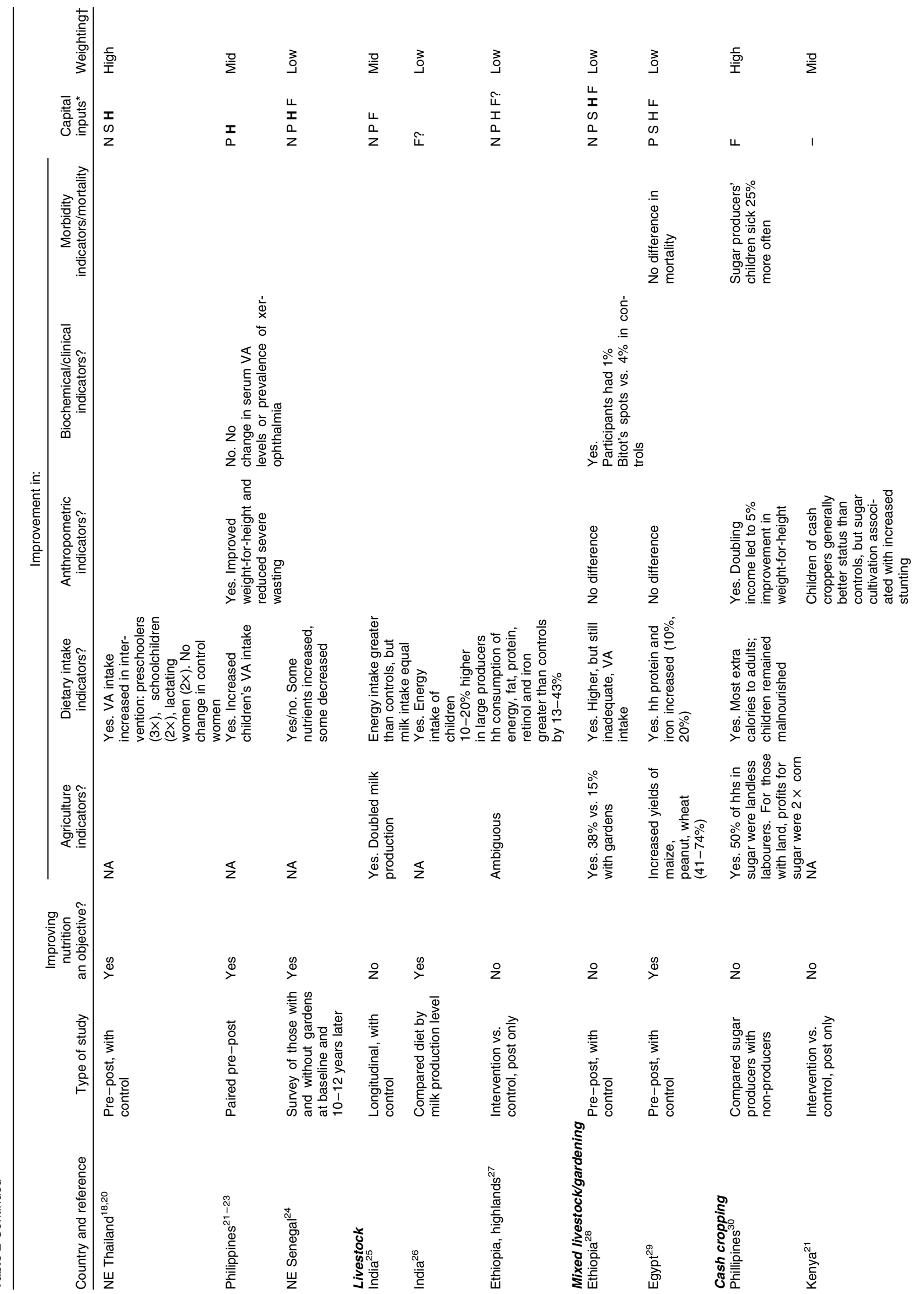




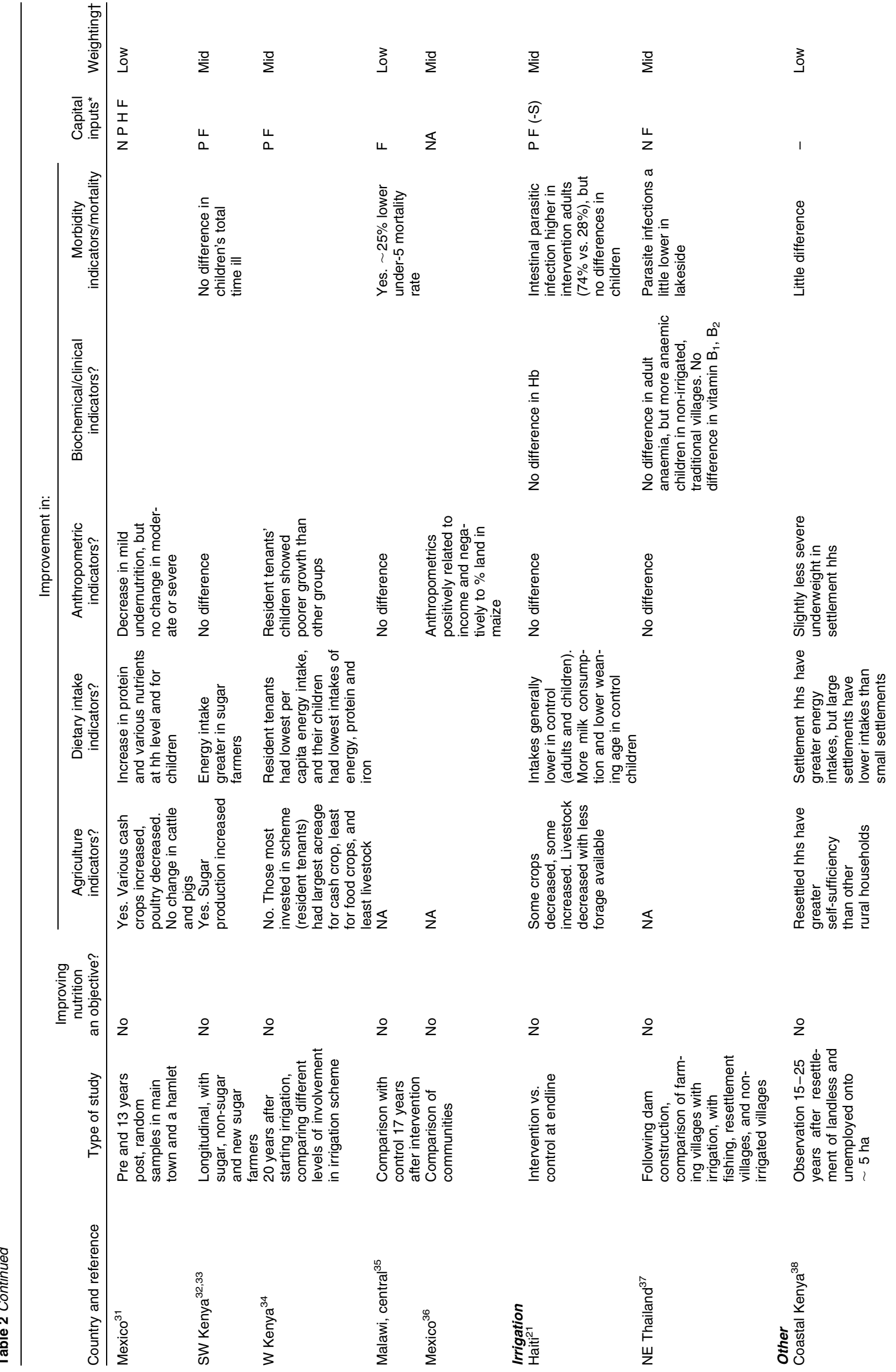


control group in terms of diet (21 of 25 cases), anthropometrics (seven of 16 cases), biochemical/clinical indicators (five of 10 cases) and morbidity (five of eight cases); see Table 3 for details.

\section{Weighting of reports as bigh, mid and low}

The relative importance, or weighting, that we gave the studies' conclusions is indicated in the last column of Table 2 by 'high', 'mid' or 'low'; 17 of the 30 projects were rated as 'high' or 'mid'. Among these 17 projects, nine showed improvement in at least one agriculture indicator. The intervention group showed improvement and/or better status than the control group in terms of diet (13 of 14 cases), anthropometrics (five of 10 cases), biochemical/ clinical indicators (three of six cases) and morbidity (three of seven cases). Negative effects were not uncommon; see Table 4 for details.

Nutrition outcome according to type of intervention Of the 17 projects which were ranked high or mid, nine had improving nutrition as an explicit objective of the project; these were the nine home gardening projects. In addition, all nine of the home gardening projects included nutrition education, and often some other public health intervention. It is therefore not possible to separate the effects of the type of intervention from the effect of the project objective or the effect of including nutrition education. These home gardening interventions had somewhat better nutrition outcomes than the other interventions. Among the home gardening interventions, there were 19 nutrition indicators combined across all projects (including diet, anthropometric, biochemical and morbidity indicators); 16 of these 19 indicators were better in the intervention group. Two indicators were worse in the intervention group, and for one indicator there was no change. In the non-home gardening interventions, only eight of the 18 indicators were better in the intervention group, five indicators were worse in the intervention group, and for five there was no difference.

\section{Nutrition outcomes by number and type of capital investments}

In general, the home gardening interventions invested in more types of capital than did the other interventions. Of the studies weighted as high and mid, seven of the nine home gardening projects invested in three or more of the types of capital, whereas the seven non-home gardening projects all invested in two or fewer types of capital. Within their human capital investments, seven of the nine home gardening projects incorporated gender considerations into the project, which may have partly been responsible for the positive effect on child dietary intake ${ }^{13,17}$, other improvements in child growth and vitamin A status ${ }^{4,8}$, and morbidity ${ }^{10,11}$. Incorporating gender considerations, which are sensitive to mothers' workloads and the central role they play in child feeding 
Table 3 Number of studies with a positive effect on diet, anthropometrics, biochemical/clinical indicators or morbidity: all studies

\begin{tabular}{|c|c|c|c|c|c|}
\hline & \multirow[b]{2}{*}{$\begin{array}{l}\text { Number } \\
\text { of studies }\end{array}$} & \multicolumn{4}{|c|}{ Positive effect/total projects (negative effect) ${ }^{\star}$} \\
\hline & & Diet & Anthropometrics & $\begin{array}{l}\text { Biochemical/clinical } \\
\text { indicators }\end{array}$ & Morbidity \\
\hline \multicolumn{6}{|l|}{ By type of intervention } \\
\hline Vegetable/home garden & 13 & $10 / 12$ & $3 / 5(1)$ & $3 / 6(1)$ & $2 / 2$ \\
\hline Livestock & 3 & $2 / 3$ & & & \\
\hline Mixed livestock/gardening & 2 & $2 / 2$ & $0 / 1$ & $1 / 1$ & $0 / 1$ \\
\hline Cash cropping & 7 & $3 / 4(1)$ & 3/7 (2) & & $1 / 2$ \\
\hline Irrigation & 2 & $1 / 1$ & $0 / 2$ & $1 / 2$ & $1 / 2(1)$ \\
\hline Other & 3 & $3 / 3$ & $1 / 1$ & $0 / 1$ & \\
\hline Total & 30 & $21 / 25(1)$ & $7 / 16(3)$ & $5 / 10(1)$ & $4 / 7(1)$ \\
\hline \multicolumn{6}{|c|}{ By 'improving nutrition' as explicit objective } \\
\hline Yes & 15 & $11 / 14$ & $3 / 5(1)$ & $3 / 6(1)$ & $2 / 4(1)$ \\
\hline No & 15 & $10 / 11(1)$ & $4 / 9(1)$ & $2 / 3$ & $2 / 6(2)$ \\
\hline \multicolumn{6}{|c|}{ By inclusion of nutrition education } \\
\hline Yes & 15 & $10 / 12$ & $4 / 6(1)$ & $4 / 6(1)$ & $2 / 3(1)$ \\
\hline No & 15 & $11 / 12$ & $3 / 10(2)$ & $1 / 2$ & $2 / 7(2)$ \\
\hline \multicolumn{6}{|l|}{ By number of capital inputs } \\
\hline 5 & 6 & $6 / 6$ & $2 / 2$ & $2 / 2$ & $2 / 2$ \\
\hline 4 & 8 & $6 / 8$ & $1 / 3$ & $1 / 3(1)$ & $0 / 2(1)$ \\
\hline 3 & 3 & $2 / 2$ & & $1 / 1$ & \\
\hline 2 & 5 & $3 / 4(1)$ & $1 / 4(1)$ & $1 / 1$ & $1 / 1$ \\
\hline 1 & 4 & $2 / 3$ & $1 / 3$ & $0 / 1$ & $1 / 3(1)$ \\
\hline 0 & 2 & $1 / 1$ & $1 / 2(1)$ & & $0 / 1$ \\
\hline$\geq 3$ & 17 & $14 / 16$ & $3 / 5$ & $4 / 6(1)$ & $2 / 4(1)$ \\
\hline$\leq 2$ & 11 & $6 / 8(1)$ & $3 / 9(2)$ & $1 / 2$ & $2 / 5$ (1) \\
\hline
\end{tabular}

*When the outcomes were mixed (some aspects of the indicator were positive, some neutral, some negative), the indicator was scored negative if there were any negative aspects.

and care, can help improve child nutrition. However, the specifics of gender considerations in the above projects were not always presented, and when presented were often limited to making women the intervention target. Some served to empower women and put them in leading roles for implementation, having them reach out to other women in the community ${ }^{13,18,19}$. All seven of the interventions with gender considerations also had inputs into social capital (e.g. participatory processes). Four of these projects also described intentional ${ }^{13}$ or unintentional $^{4,8,10,11,17}$ positive impacts on financial capital (i.e. income generation).

Some papers that did not have positive nutrition outcomes mentioned the need for nutrition and/or health education (human capital) to produce the desired nutrition effect ${ }^{31,35,37}$. One investigation assessed differences between agriculture only and agriculture plus nutrition education, and showed a dietary benefit of including nutrition education ${ }^{13}$. This design is particularly appealing, as it allows the synergistic effect of nutrition education to be quantified in a project also considering gender issues and financial capital.

\section{Discrepancies between diet and other bealth outcomes}

Many of the projects reported outcomes with multiple types of nutrition and health indicators. There were at times discrepancies between the various indicators: improved diet did not always coincide with improvements in the anthropometric, biochemical/clinical or morbidity indicators. There was no discernible pattern between the 'indicator discrepancy' and the project objectives or the type of agriculture intervention. However, discrepancies were perhaps dependent on the number of types of capital input, as outlined in Table 5, where the broader-based interventions more often had positive relationships between diet and the other indicators. It is possible that a narrowly focused intervention may hurt other aspects of livelihoods that are reflected in poor growth, anaemia or morbidity. For example, an intervention that increases the amount of time women work in the field without considering childcare may improve food availability and diet, but hurt child welfare. It is also possible that a broader consideration of capital inputs is required to have a positive effect on child welfare. These interpretations are consistent with the Sustainable Livelihoods Framework, but the data are scanty and our interpretations are tentative.

\section{Long-term effects}

Nine projects measured effects after the intervention itself was finished (from 4 to 30 years after the intervention ended). It has been assumed that positive effects on financial capital are necessary for the long-term success of agriculture interventions $s^{5,7}$. We therefore considered the long-term impacts of these nine projects in relation to their effect (intentional or not) on financial capital; see Table 6 for a summary of these projects. 
Table 4 Number of studies with a positive effect on diet, anthropometrics, biochemical/clinical indicators or morbidity: including only those studies weighted as high or mid

\begin{tabular}{|c|c|c|c|c|c|}
\hline & \multirow[b]{2}{*}{$\begin{array}{l}\text { Number } \\
\text { of studies }\end{array}$} & \multicolumn{4}{|c|}{ Positive effect/total projects (negative effect) ${ }^{\star}$} \\
\hline & & Diet & Anthropometrics & $\begin{array}{l}\text { Biochemical/clinical } \\
\text { indicators }\end{array}$ & Morbidity \\
\hline \multicolumn{6}{|l|}{ By type of intervention } \\
\hline Vegetable/home garden† & 9 & $9 / 9$ & $3 / 3$ & $2 / 4(1)$ & $2 / 3(1)$ \\
\hline Livestock & 1 & $1 / 1$ & & & \\
\hline Mixed livestock/gardening & 0 & & & & \\
\hline Cash cropping & 5 & $2 / 3(1)$ & $2 / 5(2)$ & & $0 / 2(1)$ \\
\hline Irrigation & 2 & $1 / 1$ & $0 / 2$ & $1 / 2$ & $1 / 2(1)$ \\
\hline Other & 0 & & & & \\
\hline Total & 17 & $13 / 14(1)$ & $5 / 10(2)$ & $3 / 6(1)$ & $3 / 7(3)$ \\
\hline \multicolumn{6}{|c|}{ By 'improving nutrition' as explicit objective } \\
\hline Yes & 9 & $9 / 9$ & $3 / 3$ & $2 / 4(1)$ & $2 / 3(1)$ \\
\hline No & 8 & $4 / 5(1)$ & $2 / 7(2)$ & $1 / 2$ & $1 / 4(2)$ \\
\hline \multicolumn{6}{|c|}{ By inclusion of nutrition education $†$} \\
\hline Yes & 9 & $9 / 9$ & $3 / 3$ & $2 / 4(1)$ & $2 / 3(1)$ \\
\hline No & 8 & $4 / 5(1)$ & $2 / 8(2)$ & $1 / 2$ & $1 / 4(2)$ \\
\hline \multicolumn{6}{|l|}{ By number of capital inputs } \\
\hline 5 & 4 & $4 / 4$ & $2 / 2$ & $1 / 1$ & $2 / 2$ \\
\hline 4 & 2 & $2 / 2$ & & $1 / 2(1)$ & $0 / 1(1)$ \\
\hline 3 & 2 & $2 / 2$ & & & \\
\hline 2 & 5 & $3 / 4(1)$ & $1 / 4(1)$ & $1 / 2$ & $1 / 2$ \\
\hline 1 & 2 & $2 / 2$ & $1 / 2$ & & \\
\hline 0 & 1 & & $0 / 1(1)$ & & \\
\hline$\geq 3$ & 8 & $8 / 8$ & $2 / 2$ & $2 / 3(1)$ & $2 / 3(1)$ \\
\hline$\leq 2$ & 8 & $5 / 6(1)$ & $2 / 7$ (2) & $1 / 2$ & $1 / 2$ \\
\hline
\end{tabular}

*When the outcomes were mixed (some aspects of the indicator were positive, some neutral, some negative), the indicator was scored negative if there were any negative aspects.

†The nine home gardening projects were the nine that had 'improving nutrition' as an explicit objective, and all nine included nutrition education.

Just over half (five of nine) of the projects had at least some long-term benefits as a result of the intervention. Of the seven that strengthened financial capital, only three had a positive long-term effect. This is surprising because, as Pretty and Hine ${ }^{7}$ suggest, financial capital is a key element for long-term sustainability. However, a number of the interventions strengthened financial capital at the cost of natural and social capital, suggesting that a broader-based strengthening (or at least not a weakening) of the five types of capital would be required for long-term impact. Of the seven projects that strengthened financial capital, two also strengthened some aspect of human capital $^{21,31}$ with only one of them ${ }^{31}$ having some long-term benefits; none of the seven strengthened social capital.

Table 5 Number of projects with positive, neutral or negative relationships between diet and other nutrition/health outcomes, by number of types of capital input*

\begin{tabular}{llccc}
\hline & & \multicolumn{3}{c}{ Relationship between diet and: } \\
\cline { 3 - 5 } $\begin{array}{l}\text { Number of } \\
\text { types of } \\
\text { capital input }\end{array}$ & & \multicolumn{3}{c}{$\begin{array}{c}\text { Biochemical/ } \\
\text { clinical }\end{array}$} \\
\hline$\geqq 3$ & Anthropometrics & $\begin{array}{c}\text { indicators } \\
\text { Positive }\end{array}$ & 3 & Morbidity \\
\hline 2 & $\begin{array}{l}\text { No effect } \\
\text { Negative }\end{array}$ & 1 & 5 & 2 \\
Positive & 3 & 1 & 1 \\
& $\begin{array}{l}\text { No effect } \\
\text { Negative }\end{array}$ & 2 & 2 & 2 \\
\hline
\end{tabular}

*Includes only those studies which had positive diet outcomes.
Two of the nine projects ${ }^{14,18}$ did not invest in or make an impact on financial capital. However, these two did make investments in human capital and social capital, and had long-term positive effects despite not changing financial capital (although their follow-up period was only 4-5 years). Gender considerations are also important; however, even when gender considerations are included (e.g. focusing on a 'woman's' crop), there is the potential for males to take control of crops that have or attain, through the course of the intervention, income-generating potential $^{13}$.

\section{Discussion}

Agriculture interventions had mixed results in terms of improving nutritional status in participating households. Our analysis of the agriculture and nutrition relationship was often hampered by the projects using study designs that were not suitable to assess this relationship. There is also inherent difficulty in comparing the outcomes of interventions with different objectives and inputs. In addition, it was difficult to distinguish between the effects of the type of intervention, having a nutrition objective and the types of capital investment, because of the fact that all of the home gardening interventions had an explicit nutrition objective as well as investing broadly in various types of capital, especially nutrition education (human capital).

In order to isolate the effects of the capital investments, we therefore need to consider only the non-home 
gardening interventions. There were 16 non-home gardening interventions; seven had three or more types of capital investment, nine had two or fewer. Details of the nutrition outcomes for these interventions are provided in Table 7 . Clearly the interventions with more broadly based capital investments had more positive nutrition and health outcomes, and no negative outcomes. Adding across all indicators, nine of 11 indicators were positive for the broadly based interventions, and for the more narrowly based interventions, only nine of 22 indicators were positive and five were negative. While the classification of activities into the broad categories of capital investment is certainly crude, it is useful in demonstrating that, overall, investing broadly in the target population - and not just in the agriculture intervention - does seem to improve prospects for positively impacting on the health of the people.

Among the projects reviewed, home gardening projects usually had a higher success rate than other types of intervention, with at least some positive nutrition outcomes in all nine of the projects weighted as mid and high. This may be due to home gardening being an inherently strong intervention, which most households can successfully adopt. Another explanation may be that all of these projects strengthened human capital through the use of nutrition education and/or gender considerations. From the information provided in the projects reviewed, it is difficult to determine which of these, or both, is responsible for the observed success because they are nearly mutually exhaustive (almost all home gardening projects included human capital through nutrition education and gender considerations; almost all projects investing in human capital were home gardening projects). We do know that nutrition education only interventions, without associated agricultural interventions, can result in nutrition improvement in participating households ${ }^{41}$.

The results presented here indicate that nutrition education is of central importance for achieving nutrition improvement. However, there are also examples of agriculture interventions improving nutrition outcomes without a nutrition education component. There may be an overestimate of the nutrition impact of agriculture interventions resulting from the Hawthorne effect: only those agriculture interventions that measured nutrition outcomes were considered, and it is possible that the act of observing nutrition resulted in improved nutrition outcomes, independent of any other inputs ${ }^{42,43}$.

Our review suggests that, in agriculture interventions, investing broadly in five types of capital, especially human capital, increases the prospects for nutrition improvement. While those projects that do invest in human (especially nutrition education and consideration of gender issues) and other types of capital have a greater likelihood of effecting positive nutritional change, such investment is neither sufficient nor always necessary to 
Table 7 Considering the non-home gardening interventions, the number of studies with a positive effect on diet, anthropometrics, biochemical/clinical indicators or morbidity, according to the number of types of capital input

\begin{tabular}{lccccc}
\hline & & \multicolumn{4}{c}{ Positive effect/total projects (negative effect)* } \\
\cline { 3 - 6 } $\begin{array}{l}\text { Number of types } \\
\text { of capital input }\end{array}$ & $\begin{array}{c}\text { Number } \\
\text { of studies }\end{array}$ & Diet & Anthropometrics & $\begin{array}{c}\text { Biochemical/clinical } \\
\text { indicators }\end{array}$ & Morbidity \\
\hline$\geq 3$ & 7 & $7 / 7$ & $1 / 2$ & $1 / 1$ & $0 / 1$ \\
$\leq 2$ & 9 & $4 / 6(1)$ & $2 / 8(2)$ & $1 / 2$ & $2 / 6(2)$ \\
\hline
\end{tabular}

* When the outcomes were mixed (some aspects of the indicator were positive, some neutral, some negative), the indicator was scored negative if there were any negative aspects.

effect change. It is not clear what is necessary to sustain the nutrition benefits in the years after the intervention period is completed. It is often assumed that agriculture interventions result in sustainable nutrition benefits, especially if they strengthen financial capital; however, this review does not substantiate this assumption. Further research into the question is warranted. The multidisciplinary nature of such research calls for collaboration between nutritionists, agriculture scientists and social scientists $^{44}$. The agriculture-nutrition link must be studied in a large variety of projects and settings, in order to build a body of knowledge that will complement what is presented in this review.

\section{Acknowledgements}

This work was funded in part by the Canadian International Development Agency.

The review is one component of a broader research programme, which also includes an analysis of the development outcomes in terms of the social, economic and environmental benefits of small-scale, rural agriculture interventions ${ }^{3}$.

This paper benefited from the comments of two anonymous reviewers.

\section{References}

1 Lunven P. The nutritional consequences of agricultural and rural development projects. Food and Nutrition Bulletin 1982; 4: 17-22.

2 Smitasiri S. A comment on how the nutritional impact of agricultural innovations can be enhanced. Food and Nutrition Bulletin 2001; 21: 503-6.

3 Ramírez R. The effectiveness of small-scale agriculture interventions on household food security: a review of the literature. Report prepared for the Canadian FoodGrains Bank, Interpares, Partners for Development, Oxfam Canada, Canadian International Development Agency and International Development Research Centre. Ottawa, Canada, 2002.

4 Marsh R. Building on traditional gardening to improve household food security. Food, Nutrition and Agriculture 1998; 22: 4-14.

5 Von Braun J. Agricultural commercialization: impacts on income and nutrition and implication for policy. Food Policy 1995; 20: 187-202.

6 Berti PR, Krasevec J, FitzGerald SL. Effectiveness of
Small-scale, Rural Agriculture Interventions. Part I: Nutrition Outcomes - Literature Review and Critical Analysis. Ottawa: PATH (Programme for Appropriate Technology in Health) Canada, 2002.

7 Pretty J, Hine R. Reducing Food Poverty with Sustainable Agriculture: A Summary of New Evidence. Colchester, UK: Centre for Environment and Society, University of Essex, 2001 [online]. Available at http://www2.essex.ac.uk/ces/ ResearchProgrammes/CESOccasionalPapers/Report1-19. pdf. Accessed 19 November 2001.

8 Helen Keller International (HKI)/Asian Vegetable Research and Development Centre (Taiwan). Home Gardening in Bangladesh: Evaluation Report of the Home Gardening Pilot Project. New York: HKI, 1993.

9 CARE Nepal. A study of the Evaluation of Home Gardening Program in Bajura and Mabottari Districts. Project Report. Nepal: CARE Nepal, 1995.

10 English RM, Badcock JC, Giay T, Ngu T, Waters AM, Bennett SA. Effect of nutrition improvement project on morbidity from infectious diseases in preschool children in Vietnam: comparison with control commune. British Medical Journal 1997; 315: 1122-5.

11 English R, Badcock J. A community nutrition project in Viet Nam: effects on child morbidity. Food, Nutrition and Agriculture 1998; 22: 15-21.

12 Greiner T, Mitra SN. Evaluation of the impact of a food-based approach to solving vitamin A deficiency in Bangladesh. Food and Nutrition Bulletin 1995; 16: 193-205.

13 Hagenimana V, Oyunga MA, Low J, Njroge SM, Gichuki ST, Kabira J. The Effects of Women Farmer's Adoption of Orangefleshed Sweet Potatoes: Raising Vitamin A Intake in Kenya. Research Report Series No. 3. Washington, DC: International Center for Research on Women, 1999.

14 Kidala D, Greiner T, Gebre-Medhin M. Five-year follow-up of a food-based vitamin A intervention in Tanzania. Public Health Nutrition 2000; 3: 425-31.

15 Ngu T, Quang ND, Ha PH, Giay T, Badcock JC, FitzGerald S. A food based approach to nutrition improvement through household food security in Vietnam, with special reference to vitamin A deficiency. In: Proceedings of 16th IVACG Meeting, Chang Rai, Thailand, 1994. Washington, DC: International Life Sciences Institute, 1995; 77.

16 Phillips M, Sanghvi T, Suarez R, McKigney J, Fiedler J. The costs and effectiveness of three vitamin $\mathrm{A}$ interventions in Guatemala. Social Science \& Medicine 1996; 42: 1661-8.

17 Solon F, Briones H, Fernandez JR, Shafritz LB. Moving to a long-term strategy: increasing vegetable gardening and consumption in the Philippines. In: Seidel RE, ed. Strategies for Promoting Vitamin A Production, Consumption and Supplementation. Four Case Studies. Washington, DC: Academy for Educational Development, 1996.

18 Smitasiri S, Dhanamitta S. Sustaining Behavior Change to Enhance Micro-nutrient Status: Community and Womenbased Interventions in Thailand. OMNI Research Report Series No. 2. Washington, DC: International Center for Research on Women, 1999. 
19 Smitasiri SK, Sangobwarchar P, Kongpunya C, Subsuwan O, Banjong C, Chitchumroonechokchai W, et al. Sustaining behavioural change to enhance micronutrient status through community and women-based interventions in northeast Thailand: vitamin A. Food and Nutrition Bulletin 1999; 20: 243-51.

20 Attig GA, Smitasiri S, Ittikom K, Dhanamitta S. Promoting home gardening to control vitamin A deficiency in northeastern Thailand. Food, Nutrition and Agriculture 1993; 7: $18-25$.

21 Brun TA, Geissler C, Kennedy E. The impact of agricultural projects on food, nutrition and health. World Review of Nutrition and Dietetics 1991; 65: 99-123.

22 Solon F, Fernandez TL, Latham MC, Popkin BM. An evaluation of strategies to control vitamin A deficiencies in the Philippines. American Journal of Clinical Nutrition 1979; 32: 1445-53.

23 Popkin BM, Solon FS, Fernandez T, Latham MC. Benefitcost analysis in the nutrition area: a project in the Philippines. Social Science \& Medicine 1980; 14C: 207-16.

24 Brun T, Reynaud J, Chevaussus-Agnes S. Food and nutrition impact of one home garden project in Senegal. Ecology of Food and Nutrition 1989; 23: 91.

25 Alderman H. Cooperative Dairy Development in Katnataka, India: An Assessment. Research Report 64. Washington, DC: International Food Policy Institute, 1987.

26 Begum JM. The impact of dairy development on protein and calorie intake of pre-school children. Indian Journal of Medical Sciences 1994; 48: 61-4.

27 Ahmed MM, Jabbar M, Ehui S. Household-level economic and nutritional impacts of market-oriented dairy production in the Ethiopian Highlands. Food and Nutrition Bulletin 2000; 21: 460-5.

28 Ayalew W, Gebriel ZW, Kassa H. Improving Vitamin A Intake through a Woman-focused Dairy Goat Development Project in Ethiopia. OMNI Research Report Series No. 4. Washington, DC: International Center for Research on Women, 1999.

29 Galal OM, Harrison GG, Abdou AI, Zein el Abedin A. The impact of a small-scale agricultural intervention on socioeconomic and health status. Food and Nutrition 1987; 13: $35-43$.

30 Bouis HE, Haddad LJ. Effects of Agricultural Commercialization on Land Tenure, Household Resource Allocation, and Nutrition in the Philippines. Research Report 79. Washington, DC: International Food Policy Institute, 1990.

31 Hernandez M, Hidalgo CP. Effect of economic growth in nutrition in a typical community. Ecology of Food and Nutrition 1974; 3: 283-91.

32 Kennedy E. The Effects of Sugarcane Production on Food Security, Health, and Nutrition in Kenya: A Longitudinal Analysis. Research Report 78. Washington, DC: International Food Policy Institute, 1989.

33 Kennedy ET, Oniang'o R. Household and preschooler vitamin A consumption in southwestern Kenya. Journal of Nutrition 1993; 123: 841-6.

34 Niemeijer R, Geuns M, Kliest T, Ogonda V, Hoorweg J. Nutrition in agriculture development: the case of irrigated rice cultivation. Ecology of Food and Nutrition 1988; 22: 65-81.

35 Kurth A. Agricultural development and nutritional status in Malawi. Journal of Tropical Pediatrics 1989; 35: 250-4.

36 DeWalt KM, DeWalt BR, Escudero JC, Barkin D. Shifts from maize to sorghum production: nutrition effects in four Mexican communities. Food Policy 1990; 15: 395-406.

37 Sornmani S, Schelp FP, Sesth V, Pongpaew P, Sritabutra P, Supawan V, et al. An investigation of the health and nutritional status of the population in the Nam Pong Water Resource Development Project, Northeast Thailand. Annals of Tropical Medicine and Parasitology 1981; 75: 335-46.

38 Hoorweg J, Foeken D, Klaver W, Okello W, Veerman W. Nutrition in agricultural development: land settlement in Coast Province, Kenya. Ecology of Food and Nutrition 1996; 35: $161-78$.

39 Morris SS, Medina Banegas JM. Rural development, household food safety, and nutrition in western Honduras. Archivos Latinoamericanos de Nutricion 1999; 49: 244-52.

40 Rajasekaran B. An Indigenous Duck-Fish Production System in South India. Impact on Food and Nutritional Security. Saginaw, MI: Consortium for International Earth Science Information Network (CIESIN) [online]. Available at http://www.ciesin.org/docs/004-200/004-200.html. Accessed 6 December 2001.

41 Ruel MT, Levin CE. Assessing the Potential for Food Based Strategies to Reduce Vitamin $A$ and Iron Deficiencies: Reviewing the Evidence. Washington, DC: International Food Policy Institute, 2000.

42 Rush D. Nutrition and maternal mortality in the developing world. American Journal of Clinical Nutrition 2000; 72: 212S-40S.

43 Willett WC. Letter to the Editor. American Journal of Clinical Nutrition 1999; 70: 108A-9A.

44 Pinstrup-Andersen P. Agricultural research and nutrition. Food Policy 1990; 15: 475-8. 